DOI: https:// dx.doi.org/ 10.33289/IJRPC.12.10.2021.11(41)

\title{
A REVIEW ON FLOATING DRUG DELIVERY SYSTEM
}

\section{Afrose soha* and P. Veera Lakshmi}

\author{
PG student school of pharmaceuticals science and Technologies, \\ JNTUK, Kakinada - 533 003, Andhra Pradesh, India.
}

\begin{abstract}
In recent years scientific and technological advancements have been made in the research and development of new drug delivery systems have been made by resolving physiological disorders, such as short gastric residence periods and unpredictable gastric emptying times. Gastroretentive Dosage forms (GRDF)which will be hold within the stomach. Multiple methods utilized in the prolongation of gastric duration are floating drug delivery system, swelling and expanding system, polymeric bio-adhesive system, high density system and other delayed gastric emptying system. Medication-based disease treatment is entering a replacement era during which a increasing range of innovative drug delivery technologies are getting used and are available for clinical use. Floating Drug Delivery Systems (FDDS) is one of the gastro-retentive dosage forms used to achieve extended duration of gastric residency. The main aim of writing this review on floating drug delivery systems (FDDS) was to compile the recent literature with particular specialise in the most floating mechanism to realize gastric retention. Sustained oral release of gastrointestinal dosage types provides many benefits for drugs with absorption from the upper sections of the alimentary canal and people that function locally throughout the stomach. This review includes the physiology, factors controlling gastric retention time, excipient variables influencing gastric retention, approaches to designing single-unit, hydro-dynamically balanced system and multi-unit floating structure, and aspects of their classification, formulation and evaluation are discussed intimately, and few applications of those systems.
\end{abstract}

Keywords: Gastro retentive system, floating drug delivery system and dosage form.

\section{INTRODUCTION}

The solid oral dosage forms such as capsule, tablets gives specific drug concentration in systemic blood circulation without getting any control over drug delivery system and also cause major fluctuations in plasma drug concentrations. The most convenient and preferred means of any drug delivery to the systematic circulation is the oral Administration To achieve improved therapeutic advantages the oral controlled release drug delivery system have recently been of increasing interest in pharmaceutical field. such as ease of administration of doses, patient compliance towards the product and flexibility in formulation of drug. Those drugs are eliminated quickly from the systemic circulation who are easily absorbed from gastrointestinal tract [GIT] and have short half- life. the development of sustained -controlled release oral formulations is to avoid this limitation and it is an attempt to release the drug slowly into the gastrointestinal tract and maintain the therapeutic drug concentration in the blood circulation for a long period of time. For to get maximum gastric retention of solid dosage forms is followed by the mechanisms of mucoadhesion, sedimentation, flotation, modified shape systems, expansion or by the simultaneous administration of pharmacological agents followed by gastric emptying. The classification of floating drug delivery systems (FDDS) has been described in detail on the basis of these approaches. The diminished efficiency of the administered dose due to incomplete drug release from the DDS 
caused by the relatively short gastric residence time in humans through the major absorption zone such as proximal part of GIT. Thus considerations have led to the development of oral controlled release $\mathrm{CR}$ dosage forms possessing gastric retention capabilities are the control of location of a drug delivery system, especially for drugs exhibiting an absorption window in the GI tract or drug with a stability problem, in a specific region of the GI tract offers several advantages1. To formulate a successful stomach specific or gastro retentive drug delivery system, many approaches square measure currently utilized within the prolongation of the stomachic residence times (GRT) like hydrodynamic ally balanced systems (HBS) / floating drug delivery system, low density system, raft systems incorporating alginate gels, bioadhesive or mucoadhesive systems, high density systems, super porous hydro gels and magnetic systems ${ }^{2}$

\section{DEFINITION}

Floating systems are low - density system that have sufficient resistance to float on the stomach and stay float in gastric without creating any effect on the gastric emptying rate for a long period of time. While the system floats on the gastric contents the drug will be released slowly at the desire concentration in the system. Thus, the residue will be cleared from the stomach. Then these results will conduct to GRT elevation and be better control of flux in plasma drug concentrations. It also useful for proximal gastrointestinal tracts local drugs for example antibiotics for Helicobacter pylori on the manage for a peptic ulcer and for drugs that difficult to dissolve or not stable in intestinal fluids ${ }^{3}$

\section{STOMACH ANATOMY}

The basic operate of the abdomen is to method and transport food in tittle intestine the duration of food is tiny and largely protein square measure digestible. Structurally the abdomen is split into 3 regions: structure, body, and pylorus. the average $\mathrm{pH}$ in fasted healthy person is one $.1 \pm 0.15$, once intake of food the $\mathrm{PH}$ scale rises to the level of 3.0 to 4.0. ${ }^{3}$

Migrating myoelectric cycle (MMC) is further divide into four phases. They are

1. Phase I (basal phase)

2. Phase II (pre burst phase)

3. Phase III (burst phase)

4. Phase IV.

\section{Phase I}

In this phase the gastric emptying rate is slow as the onset of MMC is delayed. this phase usually lasts for 30 to $60 \mathrm{~min}$. Contraction does not occur in this phase. it is also known as basal phase.

\section{Phase II}

In this phase bile secretion and mucus discharge take place and intermediate contraction occurs. It lasts for $20-40$ mins. It is also known as pre- burst phase. The intensity and frequency increase gradually as the phase progresses.

\section{Phase III}

In this phase, regular and intense contraction take place for a short time. It last usually for 10-20 min. this phase also called as housekeeper wave as it tends to empty the fasting contents of the stomach. Large objective remains in the stomach in the stomach in the fed state but passed down to the intestine during this phase.

\section{Phase IV}

Last for 0 - 5 minutes and occur between phase III and I of 2 consecutive cycle. After the ingestion of a mixed meal, the pattern of contractions changes from fasted to that of fed state. This also known as digestive motility pattern and comprises continuous contraction as in phase II of fasted state. During the fed state onset of MMC is delayed resulting in slowdown of gastric emptying rate ${ }^{4}$

\section{Need for gastric retention}

- Drugs that are absorbed from the proximal a part of the canal (GIT). Drugs that are less soluble or are degraded by the alkaline $\mathrm{pH}$ they encounter at the lower a part of GIT.

- Drugs that are absorbed due to variable internal organ evacuation time. Local or sustained drug delivery to the abdomen and proximal bowel to treat bound conditions.

- Mostly very useful for the treatment of peptic ulcers caused by Helicobacter pylori infections ${ }^{1}$

\section{APPROACHES OF STOMACH RETENTION}

Various approaches are pursed to extended the retention of Associate in Nursing oral dose type within the abdomen for instance, bioadhesive approach during which the adhesive capability of some chemical compounds with conjugated protein is closely applied to the animal tissue surface of abdomen.

\section{High density approach}


For making ready such variety of formulation, the density of the pellets ought to be over the abdomen fluid. It might be a minimum of one $50 \mathrm{G} / \mathrm{ml}$ during this kind the drug will be coated or mixed with significant, nontoxic material like sulfate oxide, etc.

\section{Low density approach: floating systems come back}

Below tenuity approach during this approach, the density of pellets ought to be but one $\mathrm{g} / \mathrm{ml}$ thus on float the pellets or tablets within the internal organ fluid and unleash the drug slowly for a extended amount of your time.

\section{FACTOR AFFECTING GASTRIC RETENTION}

Factor affecting gastric emptying. The most vital parameters touching stomachal remotion and hence, the stomachal retention time of oral indefinite quantity forms include:

1. Density: GRT may be operated of indefinite quantity kind buoyancy that's obsessed with the density.

2. Size: indefinite quantity kind units with a diameter of quite seven. $5 \mathrm{~mm}$ or reportable to possess Associate in Nursing exaggerated GRT compared those with diameter of nine $.9 \mathrm{~mm}$

3. Single and multiple unit formulation: Multiple unit formulations show a lot of inevitable unharness profile and insignificant impairing of performance thanks to failure of units, permit co administration of units with totally different unharness profiles.

4. Fed or unfed state: Under fast conditions the Gl motility is characterised by periods of study motor active or the migrating myoelectric advanced (MMC) that happens each 1.5 to 2 hours.

5. Nature of meal: Feeding of inedible polymer or carboxylic acid salts will modification the motility pattern of the abdomen to a fed state decreasing the stomach remotion rate and prolonging drug release

6. Calories content: GRT is exaggerated by four to ten hours with a meal that's high in protein and fats.

7. Frequency of feed: The GRT will increase by over 400 minutes once sequent meals are given.

8. Gender: Mean mobile GRT in male (3.4 \pm 0.6 hour) is a smaller amount compared with their age and race matched feminine counterpart (4.6 \pm 1.2 hours)
9. Age: senior individuals, particularly those over seventy, have a considerably longer GRT.

10. Biological factor: polygenic disorder and Crohn's disease, stress etc.

11. Posture - GRT will vary between supine and upright mobile state of the patient $^{2}$

\section{FLOATING DRUG DELIVERY SYSTEMS (FDDS)}

These formulations have very low density and so float over gastric materials.

\section{Bioadhesive systems}

They are fix with stomach mucosa and hence, give the localized retention of the system.

\section{Swelling systems}

These systems absorb water and get enlarged sized by swelling.

\section{High density systems}

These are stays in the stomach for longer period of time, by setting down to the folds of stomach ${ }^{1}$.

Floating systems are low density systems that have maximum buoyancy to float on the gastric material and remain in the stomach for the longer period of time. A minimum stomachic content required to allow proper achievement of the bouncy retention principle, a minimum floating force $(F)$ is also to required to keep the dosage form to be buoyant on the surface of gastric content. The force equivalent to $\mathrm{F}$ that is required to maintain the submerged dosage form force $F$ is on higher positive

$$
\text { F=F (buoyancy) }-F \text { (gravity) = (DF-Ds) g.v -------(1) }
$$

Where

$F=$ total vertical force

$\mathrm{DF}=$ fluid density

Ds = object density

$\mathrm{V}=$ volume and $\mathrm{g}=$ acceleration due to gravity

\section{Mechanism of floating system}

Various attempts have been made up to retain the dosage form in the stomach as a way of increasing the retention time. These attempts include introduction floating dosage forms mucoadhesive systems, high - density system, modified shape system, gastric emptying delaying drugs. Among these the floating dosage forms are the most commonly used. Floating drug delivery systems FDDS. Have bulk density less than gastric fluids and so remain buoyant in the stomach without affecting the gastric emptying rate for a prolong period of time. While the system is floating on the gastric contents the drug is 
released slowly at the desired rate from the system. After release of drug the residual system is eliminated from the stomach. This results in an increased GRT and a better control of the fluctuation in plasma drug concentration.

oral dosage forms (capsule or tablet) that are designed to prolong the retention time of the drug within the Gl tract. The recent literature survey shows that interest increased in academics and industrial research regarding the development of novel dosage forms that can be sustained in the stomach for a longer and predictable period of time. The numerous marketed FDDS are given in table.

MARKETED PREPARATIONS OF FDDS

\begin{tabular}{|c|c|c|}
\hline Product & $\begin{array}{l}\text { Active Ingredient } \\
\text { (dose) }\end{array}$ & Remarks \\
\hline Madopar ${ }^{x}$ & $\begin{array}{l}\text { Levodopa (100mg). } \\
\text { Benserazide ( } 25 \mathrm{mg})\end{array}$ & Floating. $C R$ capsule \\
\hline Valrelease $^{x}$ & Diazepam (15mg) & Floating capsule \\
\hline Topalkan ${ }^{x}$ & $\begin{array}{l}\text { Aluminum magnesium } \\
\text { antacid }\end{array}$ & $\begin{array}{l}\text { Floating liquid alginate } \\
\text { preparation }\end{array}$ \\
\hline $\begin{array}{l}\text { Almagate } \\
\text { FloatCoat }\end{array}$ & Antacid & Floating dosage form \\
\hline $\begin{array}{l}\text { Liquid } \\
\text { Gaviscon }\end{array}$ & $\begin{array}{l}\text { Alginic acid and } \\
\text { sodium bicarbonate }\end{array}$ & $\begin{array}{l}\text { Effervescent floating liquid } \\
\text { alginate preparation }\end{array}$ \\
\hline Conviron $^{x}$ & Ferrous sulphate & Colloidal gel forming FDDS \\
\hline Cifran $O D^{x}$ & Ciprofloxacin $(1 \mathrm{~g})$ & Gas generating noating form \\
\hline Cytotec ${ }^{x}$ & $\begin{array}{l}\text { Misoprostol } \\
(100 \mathrm{mcg} / 200 \mathrm{mcg})\end{array}$ & Bilayer floating capsule \\
\hline
\end{tabular}

\section{Classification of floating drug delivery system}

\section{(A) Effervescent FDDS}

1. Gas generating system.

2. Volatile liquid containing system

\section{(B) Non - Effervescent FDDS}

1. Colloidal gel barrier system.

2. Microporous compartment system

3. Floating microspheres / micro balloons

4. Alginate floating beads 9 .

\section{(C)Raft forming system}

(A)Effervescent system

Effervescent systems include use of gas generating agents, carbonates (e.g Na bicarbonate) and alternative organic acid (e.g acid and salt acid) gift within the formulation to supply $\mathrm{CO} 2$ gas so reducing the density of system and creating it float on the gastric fluid. an alternate the incorporation of matrix containing portion of liquid that manufacture gas that evaporate at body temperature. ${ }^{7}$

\section{Gas generating systems}

These are formulated by intimately mixing the CO2 generating agents and the drug within the matrix tablet. these have a bulk density lower than gastric fluids and therefore remain floating in the stomach unflattering the gastric emptying rate for a prolonged period.

\section{Volatile liquid vacuum containing systems}

This system is created to float within the abdomen owing to floatation chamber which can be a vacuum or full of air or a harmless gas, whereas drug reservoir is encapsulated within a microporous compartment. ${ }^{8}$

\section{(B) Non- Effervescent system}

This type of system when swallowing swell unrestrained via inhibitions of viscus fluid to associate extent that it prevents their exit from the abdomen. these systems could also be remarked because the plug type system since they need a bent to stay lodged close to pyloric valve. One in all formulation strategies of such indefinite quantity forms involves the blending of drug with a gel that swells involved with viscus fluid when oral administration and maintains a relative integrity of form and a bulk density of but one inside the outer jelly like barrier. the air at bay by the swollen compound confers buoyancy to the current indefinite quantity forms. The foremost normally used excipient is non effervescent floating drug delivery system area unit gel forming or extremely swell able polysaccharide sort hydrocolloids, polysaccharides and matrix forming polymers like polyacrylate, polymethacrylate and polycarbonate. ${ }^{9}$

\section{Colloidal gel barrier systems (hydrodynamic balanced system)}

This system prolong gastric retention time and maximizes the amount of drug that reaches its absorption site in the solution form. It essentially contains drug with gel -forming hydrocolloids to remain buoyant on the stomach content. Such as polycarbophil, polystyrene and polyacrylate. upon contact with gastro intestinal fluid the hydrocolloid in 
the system hydrates to generate a colloid gel barrier to its surrounding ${ }^{11}$

\section{Microporous compartment systems}

This technology incorporates the encapsulation technique of a drug reservoir inside a microporous compartment along with pores at top and bottom walls. In the stomach the floatation chamber composed of entrapped air causes the delivery system to float over the gastric content ${ }^{11}$

1. Floating Microspheres / Micro balloons

Hallow microspheres also are known as micro balloons are considered as a most efficient buoyant system. It is composed of central hallow space inside the microsphere. Hallow microsphere is loaded with a drug in their outer polymer shelf are fabricated by a novel solvent diffusion method for emulsion. ${ }^{10}$

\section{Alginate beads / Floating beads}

Multi - unit floating dosage forms have been developed from calcium alginate spherical beads of about $2.5 \mathrm{~mm}$ in diameter and can be fabricated by adding sodium alginate solution into aqueous solution of calcium chloride, resulting in the precipitation of calcium alginate, the beads are further separated, snap - frozen in liquid nitrogen and freeze - dried at $400^{\circ} \mathrm{C}$ for $24 \mathrm{hrs}$ leads to generation of a porous system. this fabricated system would maintain a floating force for over $12 \mathrm{hrs}$ and these floating beads provide a longer residence time of more than 5.5 hrs. ${ }^{11}$

\section{(C) Raft- forming systems}

Raft - forming system are in much attention for the delivery of antacid and drug delivery for gastro infection and disorders. On contact with gastric fluid, a gel - forming solution swells and forms a viscous of gastric fluid thus facilities release drug slowly in the stomach. ${ }^{11}$

\section{ADVANTAGES OF FDDS}

1. Floating dosage form such as tablets or capsules will remains in the solution for prolonged time event alkaline $\mathrm{pH}$ of the intestine.

2. FDDS are advantages for drugs meant for local action in the stomach e:g Antacids .

3. FDDS dosage forms are advantage in case of vigorous intestinal movement and in diarrhoea to keep the drug in floating condition in stomach to get a relatively better response.

4. Acidic substance like aspirin causes irritation on the stomach wall when come in contact with it hence FDDS formulation may be useful for the administration of aspirin and other similar drugs.

5. The FDDS are advantages for drugs absorbed through the stomach e:g ferrous salts .

6. Slow release of the drug into the body minimize the counter activity leading to higher drug efficacy.

7. FDDS reduce the drug concentration fluctuation over a critical concentration and thus enhance the pharmacological effects and improves the clinical outcomes.

8. A floating dosage form is a widely accepted approach especially for drugs which have limited absorption site in upper small intestine. ${ }^{12}$

\section{DISADVANTAGES OF FDDS}

1. This system required a high level of fluid in the stomach for drugdeliveryto float and work efficient coat.Not suitable for drugs that have solubility or stability problem in GIT.

2. Drugs such as Nifedipine (calcium channel blocker) which is well absorbed along the entire GIT and which undergoes first pass metabolism, may not be desirable.

3. Drugs which are irritated to gastric mucosa are also not desirable or suitable.

4. The drug substance that are unstable in the acidic environment of the stomach are not suitable.

5. The dosage form should be administrated with a full glass of water.

6. The dosage form should be administered with a full glass of water (200- $250 \mathrm{ml})$

7. Primarily absorbed from stomach and upper part of $\mathrm{Gl}$ tract e.g calcium supplement, chlordiazepoxide and cinnarizine. $^{13}$

\section{Drugs that suitable for Floating drug} delivery systems

- Drugs that act locally in the stomach e.g $\mathrm{H} 2$ receptor antagonist, antacids and misoprostol.

- Drugs that degrade in the colon e.g ranitidine HCL and metronidazole.

- Drugs that disturb normal colonic bacteria e.g: amoxicillin, trihydrate. 
- Narrow absorption window in Gl tract e.g, riboflavin and levodopa

Polymers and other ingredients of FDDS ${ }^{14}$

\begin{tabular}{|c|c|}
\hline Polymers & Ingredients \\
\hline $\begin{array}{l}\text { HPMC k4 M, HPMC k15, HPMC } 4000 \text {, Calcium } \\
\text { alginate, Eudragit L-100, Eudragit S-100, } \\
\text { propylene foam, polyethylene oxide, sodium } \\
\text { alginate, PVP, CMC, chitosan, PVA, } \\
\text { polyethylene glycol, polycarbonate, HPC, Acrylic } \\
\text { polymer. }\end{array}$ & $\begin{array}{l}\text { - Inert fatty material } 5 \%-75 \% \text {. These } \\
\text { include fatty acid,Bee wax and chain fatty } \\
\text { alcohols. These are used to decreased } \\
\text { the hydrophilic properties. } \\
\text { - Effervescent Agents. Sodium bicarbonate, } \\
\text { citric acid, tartaric acid, Di- SGC, CG } \\
\text { Release accelerant (5\%-60\%) Lactose, } \\
\text { mannitol. } \\
\text { - Release retardants (5\%-60\%). } \\
\text { Magnesium stearate, talc, Dicalcium } \\
\text { phosphate. } \\
\text { Buoyancy increasing agents. Ethyl } \\
\text { cellulose Low Density material PVP. }\end{array}$ \\
\hline
\end{tabular}

\section{Application of FDDS}

Floating drug delivery offer many application for medication having poor bioavailability owing to the narrow absorption window within the higher apart of the epithelial duct. It retain the indefinite quantity type at the location of absorption and so enhances the bioavailability. These are summarized as:

\section{Sustained drug delivery}

The generally downside of short stomachic duration encountered with associated the atomic number 24 formulation thence are often overcome with these systems. HBS systems will stay within the abdomen for long amounts and then will unleash the drug over a chronic period of your time. These systems have a system are comparatively giant in size and spending from the opening gap is prohibited E.g sustained unleash floating capsules of nicardipine coordination compound were developed and were evaluated invivo. ${ }^{15}$

\section{Site specific Drug Delivery}

These systems are notably advantageous for medication that are specifically absorbed from abdomen or the proximal a part of the tiny viscus Eg diuretic drug and vitamin B2. E.g diuretic drug is primarily adsorbed from the abdomen followed by the small intestine. Its been rumoured that a monolithic floating indefinite quantity type with prolonged stomachic duration was developed and also the bioavailability was enhanced. AUC obtained with the floating indefinite quantity was about one 8 times those of typical diuretic drug indefinite quantity form. ${ }^{16}$

\section{Absorption Enhancement}

Drugs that have poor bioavailability as a result of site specific absorption from the higher a part of the channel area unit potential candidates to be developed as floating drug delivery systems. There by rising their absorption E.g A significantly increase within the bioavailability of floating dose forms can be achieved as compared with commercially on the market dose type. ${ }^{17}$

\section{Maintenance of constant blood level}

These systems give a straight forward manner of maintaining constant blood level with Associate in Nursing simple administration and higher patient compliance ${ }^{18}$

\section{Evaluation of stomach specific FDDS \\ 1. Determine of floating lag time}

The basic mechanism behind floating was carbonated is present within the formulation as insoluble dispersion and have become soluble within the acidic medium. Released metal ions and carbonic acid gas, caused gelation of compound and discharged gas get entrapped in gel matrix, that caused matrix system to float ${ }^{19}$

\section{Gelling capacity}

The gelling capability made up our minds by placing 10 cubic centimetre of solution in a hundred 
cubic centimetre of stirred up stomachic fluid freshly ready and equilibrated at $37 \pm 0.5^{\circ} \mathrm{C}$ and visually assessing the gel formation and nothing the time for gelation and therefore the time taken for the gel shaped to dissolved, totally different weights were assigned as per the gel integrity, weight and rate of formation of gel with respect to time $e^{20}$

\section{In Vitro Gelling Capacity}

To evaluate the formulation for their in-vitro gelling capability by visual technique, coloured solution of in place gel forming drug delivery system were ready. The in-vitro gelling capability of ready formulation was measured by putting $5 \mathrm{ml}$ of gelation resolution in a very $15 \mathrm{ml}$ salt glass tubing and maintained at $37 \pm 1^{\circ} \mathrm{C}$ temperature. $1 \mathrm{ml}$ of coloured formulation resolution was added with the assistance of measuring system. The formulation was transferred in such some way that places the measuring system at surface of fluid in tubbing and formulation was slowly free from the measuring system. Colour was incorporated to allow visualised look to fashioned gel. The in vitro gelling capability was ranked in 3 classes on idea of gelation time and fundamental measure that they fashioned gel remains. Gels once couple of minutes, spread rapidly gelation immediate remains for 12 hours gelation immediate remains for over 12 hours. ${ }^{21}$

4. Measurement of water uptake by the gel

The water uptake by the gel of the chosen formulation of metal alginate were determined by a straight forward methodology. during this study the inplace gel fashioned in forty millilitre of $0.1 \mathrm{~N}$ $\mathrm{HCL}$ was used. Form every formulation the gel portion from the $0.1 \mathrm{~N} \mathrm{HCL}$ was separated and therefore the excess $\mathrm{HCL}$ resolution was obliterated with a paper. The initial weight of the gel taken was weighed and to the present gel $10 \mathrm{ml}$ of water was added and once each half hour of the interval water was decanted and therefore the weight of the gel was recorded and therefore the distinction within the was calculated and then reported. ${ }^{22}$

\section{Invitro Drug Release study}

The in vitro unharness rate of levetiracetam from sustained release in place gel was performed using USP equipment fitted with paddle over disk at $37 \pm$ zero. $50 \mathrm{C}$ using $500 \mathrm{cc}$ of $0.1 \mathrm{~N} \mathrm{HCL}$ as a dissolution medium. This speed was slow enough to avoid the breaking of gelled formulation and was maintaining the gentle agitation condition believed to exist in vivo. The predetermine time interval, five cc sample were withdraw filtered, diluted and assayed at given wavelength using a ultra violet light 1800 double beam spectrophotometer. Accumulative share drug release was calculated using an equation obtained from a standardization curve

\section{6. pH Measurement}

The $\mathrm{pH}$ was measured in each of the solution of $\mathrm{Na}$ alginate based in place solutions, using a mark digital $\mathrm{pH}$ meter at $27^{\circ} \mathrm{c} .{ }^{23}$

\section{Physical Appearance}

All the prepared in place gel was check for their clarity and also the type time required for gel formation duration of floating and type gel formed. the measurement of every information was in triplicate and average conclusion was taken ${ }^{24}$

\section{Determination of drug content}

Accurately $10 \mathrm{ml}$ of in-suit gel from different batches were measured and transferred in to a $100 \mathrm{ml}$ of volumetric flask to the current $50-70$ $\mathrm{ml}$ of $0.1 \mathrm{~N} \mathrm{HCl}$ was more and sonicated for 30 mins. Volume was adjusted to a $100 \mathrm{ml}$. Complete dispersion of contents were ensured visually and filtered using what man filter paper. From this answer $10 \mathrm{ml}$ of sample was withdrawn and diluted to a hundred $\mathrm{ml}$ with $0.1 \mathrm{~N}$ $\mathrm{HCl}$. contents of metoclopramide $\mathrm{HCl}$ determine spectrophotometrically with using reference wavelength double beam UV - visible photometer ${ }^{25}$. 


\section{CONCLUSION}

The floating drug delivery framework was set up in an exertion the gastric maintenance time of the measurements structure and to control tranquilize discharge. One of the most doable methodologies for accomplishing a delayed and unsurprising delved conveyance profiles in the gastrointestinal tract is to control the gastric living arrangements time, utilizing gastro- retentive dose frames that will furnish us with new and significant helpful alternatives. Coasting lattice tablets are intended to drag out the gastric living arrangement time after oral organization at a specific site and controlling the arrival of medication particularly helpful for accomplish delayed gastric maintenance an enormous number of organization are centering towards commercializing this system.

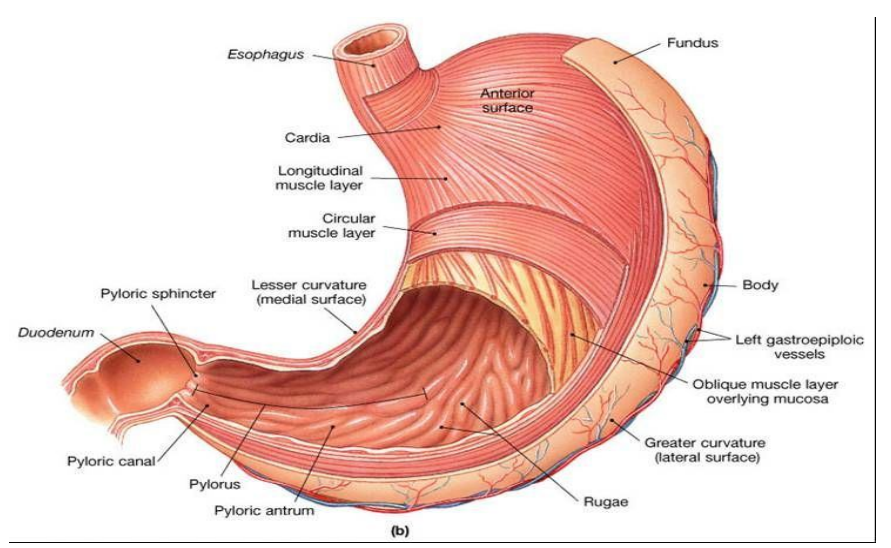

Fig. 1: Anatomy of stomach

Fig. 2: GIT motility pattern

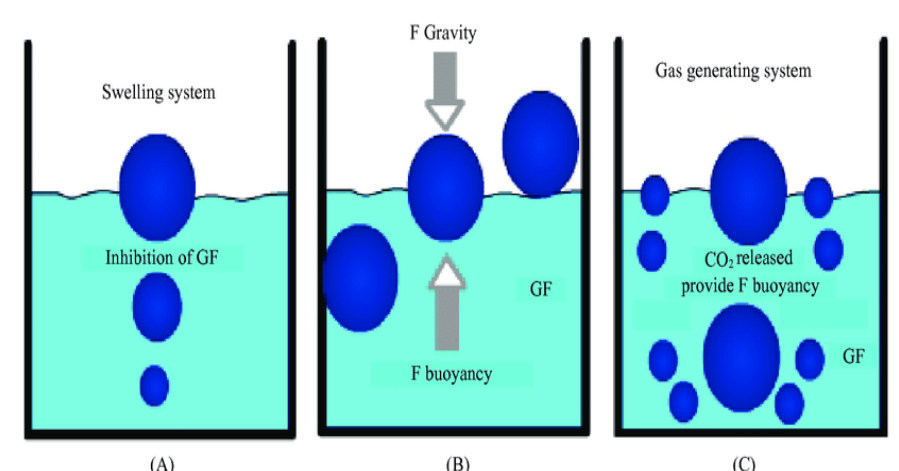

Fig. 3: mechanism of floating system

\section{REFERENCES}

1. Baviskar $P$, Patil $P$ and Saudagar RB. Floating Drug Delivery System: A comprehensive review, Journal of Drug Delivery and Therapeutics. 2019; 9(3-s):839-846. http://dx.doi.org/10.22270/jddt.v9i3s.2945.

2. Shinde Jitendra V, Malshikare Swapnali S and Chavanrajashree S. A Review on Floating Drug Delivery System. Published in International Journal of Trend in Scientific Research 
and Development (ijtsrd). 2020;4(3):427-433.

3. Iyan Sopyan, Sriwidodo, Retno Wahyuningrum and Norisca Aliza P. A review: Floating drug delivery system as a tool to improve dissolution rate in gatric. Int J App Pharm. 2020;12(4): 51-54.

4. Vijay Sharma, Rathore DS and Amit Kumar. Floating drug delivery system. A review International Journal of Medical and Biomedical Studies (IJMBS). 2020;4(8):23-30.

5. Geetha A, Kumar JR, Mohan $K$ and Sateesh V. A Review on Floating Drug Delivery Systems. Int J Pharm Res. Biomed. Anal. 2012

6. Chikhalikar SS and Wakade RB. Floating Drug Delivery System - An Approach To Oral Controlled Drug Delivery. International Journal of Pharm Tech Research. 2012;4(4):1812-26.

7. Jegadeesh Nagigoti and Shayeda. Floating Drug Delivery System. Int J Pharm Scien Nano. 2009;595-601.

8. Majethiya KA and Patel MR. Review on: Gastro retentive Drug Delivery System. International Journal of Universal Pharmacy and Bio Sciences. 2010;2(1):103-120.

9. Jayswal BD, Yadav VT, Patel KN, Patel BA and Patel PA. Formulation and Evaluation of Floating In Situ Gel Based Gastro Retentive Drug Delivery of Cimetidine. International Journal for Pharmaceutical Research Scholars (IJPRS). 2012;1(2):327-337.

10. Burns S, Attwood D and Barnwell SG. Assessment of a dissolution vessel designed for use with floating and erodible dosage forms. Int J Pharm. 1998;160:213-8.

11. Joseph N, Laxmi $S$ and Jayakrishnan A. A floating type oral dosage form for piroxicam based on hollow microspheres: in vitro and in vivo evaluation in rabbits. J Controlled Release 2002;79:71-9.

12. Singh Amit Kumar and Arora Vandana. Formulation and In vitro Evaluation of Glipizide as Floating Drug Delivery system with Natural Polymer (Gur -Gum). Journal of Pharmaceutical and Scientific Innovation. 2012;1:24- 28.

13. Kataria Sahil, Middha Akanksha, Bhardwaj Sudeep and Sandhu Premjeet. Floating Drug Delivery System: A Review; International
Research Journal of Pharmacy. 2011;2(9):18-24.

14. Chretien C, Boudy V, Allain P and Chaumei JC. Indomethacin release from ion-exchange microspheres: impregnation with alginate reduces release rate. Journal of Controlled Release 2004;96:369-78.

15. Mathur $P$ and Verma N. Floating drug delivery system. An innovative acceptable approach in gastro retentive drug delivery. Scholars Research Library. 2010;2(2):257-70.

16. Hardenia SS, Jain $A$, Patel $R$ and Kaushal A. Floating Drug Delivery Systems: A Review. Asian Journal of Pharmacy and Life Science. 2011;1(3):284-93.

17. Chandel A, Chauhan K, Parashar B, Kumar $\mathrm{H}$ and Arora S. Floating drug delivery systems: A better approach. International Current Pharmaceutical Journal. 2012;1(5):110-18.

18. Shah SH, Patel JK and Patel NV. Stomach specific floating drug delivery system: A review. International Journal of Pharmaceutical Technology and Research. 2009;1(3):623-33.

19. Gopala Krishnan S and Chenthilnathan A. Floating drug delivery system: A review. Journal of Pharmaceutical Science and Technology. 2011;3(2):548-54.

20. Vedha $\mathrm{H}$ and Chaudhary J. The recent developments on gastric floating drug delivery system: An overview. Journal of Pharmaceutical Technology and Research. 2010;2(1):524-34.

21. Kamalakkannan V, Puratchikody A, Prasanth VV and Masilamani K. Enhancement of Drugs Bioavailability by Floating Drug Delivery System - A Review. International Journal of Drug Delivery. 20111:558-70.

22. Shubhrajit $M$, Thilothama $L R$ and Shashanka D. Formulation and in vitro evaluation of metoprolol succinate floating tablets by using two viscosity grade of HPMC. International Journal of Pharmaceutical Science and Research. 2012;3(9):3507-13.

23. Narang N. AN Updated Review On: Floating Drug Delivery System (FDDS). International Journal of Applied Pharmaceutics. 2011;3(1):1-7.

24. Chandiran S, Kumar BP and Narayan V. Formulation and in vitro evaluation of floating drug delivery system for salbutamol sulphate. International Journal of pharma Biomed Sciences. 2010;1(1):12-15. 
25. Dhole AR, Gaikwad PD, Bankar VH and Pawar SP. A Review on Floating Multiparticulate Drug Delivery System: A Novel Approach to Gastric Retention. International Journal of Pharmaceutical Sciences Review and Research. 2011;6(2):211-205.

26. Vijay Sharma, Rathore DS and Amit Kumar. Floating drug delivery system: A review International Journal of Medical and Biomedical Studies (IJMBS). 2020;4(8):23-30.

27. Haridwar Lodh, Sheeba, Prabhat Kumar Chourasia and Harshitha Arun Pardhe. Floating Drug Delivery System, American Journal of Pharm Tech Research 2020.
28. Chudiwal V, Shahi S, Chudiwal S and Ahale D. Innovative Technologies for Gastro-Retentive Drug Delivery Systems. Asian Journal of Pharmaceutical Education and Research. 2017; 6(4):22-28.

29. Harshal S, Chetan G, Surbhi $U$ and Sujit $P$. Development and in vitro evaluation of an oral floating tablet of metronidazole. J Drug Delivery Ther. 2018;8:83-6.

30. Setia M, Kumar K and Teotia D. Gastro-retentive floating beads a new trend of drug delivery system. Journal of Drug Delivery and Therapeutics. 2018;8(3):169-180. 